\title{
Time-intensity transformation and internal stress in UV-curable hyperbranched acrylates
}

\author{
Lars Erik Schmidt • Daniel Schmäh • Yves Leterrier • \\ Jan-Anders E. Månson
}

Received: 2 June 2006 / Accepted: 20 December 2006 / Published online: 17 February 2007

(C) Springer-Verlag 2007

\begin{abstract}
The photocuring of three different highly functional acrylates-Di-pentaerythritol penta/hexaacrylate (DPHA) and two hyperbranched molecules (HBP), one with a stiff polyester and one with a more flexible polyether structure - was investigated by means of photorheology, photo differential scanning calorimetry, and beam bending. Special attention was paid to the influence of the composition of DPHA/HBP reactive blends and UV intensity on gelation and vitrification and the resulting dynamics of the internal stress. It was found that adding HBPs to DPHA did not influence gelation significantly, but shifted the onset of vitrification to higher conversions and thus caused lower internal stresses in the material. Increasing UV intensity increased both the conversion at vitrification, thus retarding the build-up of internal stresses, and the ultimate conversion, thus increasing the final stress level. The obtained conversion, gelation, and vitrification data were assembled into time-intensity transformation diagrams, thus providing a useful tool for optimizing photocuring.
\end{abstract}

Keywords Gelation · Residual stress · Crosslinking ·

Vitrification $\cdot$ Photopolymerization $\cdot$ Acrylates

\begin{abstract}
Abbreviations
HBP hyperbranched polymer

DSC differential scanning calorimetry
\end{abstract}

This paper was presented at Annual European Rheology Conference (AERC) held in Hersonisos, Crete, Greece, April 27-29, 2006.

L. E. Schmidt • D. Schmäh · Y. Leterrier · J.-A. E. Månson $(\bowtie)$ Laboratoire de Technologie des Composites et Polymères (LTC), Ecole Polytechnique Fédérale de Lausanne (EPFL),

1015 Lausanne, Switzerland

e-mail: jan-anders.manson@epfl.ch

\section{Introduction}

Time-temperature transformation diagrams (TTT diagrams), as first proposed by Gillham and Enns (Enns and Gillham 1983; Gillham 1983), are extensively used for the evaluation and design of thermoset-curing processes. In these diagrams, the physical state of the curing thermoset is plotted as a function of curing time and temperature. They usually contain information about gelation, vitrification, and thermally induced de-polymerization. In the case of UV-curable systems, light intensity, rather than temperature, is used to control reaction rate. Understanding the influence of UV intensity on network formation mechanisms and resulting mechanical properties helps to optimize the processing conditions and ensure that desired material properties are obtained. A time-intensity-temperature transformation diagram was implemented recently for UV curing of acrylates (Lee et al. 2003). These authors showed that vitrification shifted to shorter times by increasing light intensities, whereas for gelation, only a slight shift was observed, although the conversion state of the acrylate was not included. These results seem to contradict the previous work indicating weak influence of light intensity on conversion at vitrification (Schmidt et al. 2007). Compilation of conversion and structural data in a comprehensive time-intensity transformation diagram should help clarifying this issue.

Chemical conversion during photocuring is usually measured by photo differential scanning calorimetry (photo DSC; Jakubiak et al. 2001) and real-time Fourier transform infrared spectroscopy (RTIR; Decker and Moussa 1988). The stiffness build-up during photo-polymerization can be recorded by photorheology, dating back to 1992 when Khan et al. (1992) investigated UV curing of thiolene systems. Further studies proved that this technique is also 
able to resolve structural features, as for example gelation (Chiou et al. 1996, 1997). A first approach to increase time resolution, and hence the measurable UV-intensity range, was made by Lee et al. (2000). To further increase the time resolution and detectable stress range, and thereby make photorheology applicable for samples cured under higher UV intensities, a novel approach was developed by the authors (Schmidt et al. 2005a,b). To correlate the stiffness build-up with chemical conversion, two recent studies combined Fourier transform infrared spectroscopy with photorheology (Botella et al. 2004; Steeman et al. 2004). These studies indicate that UV intensity has a strong effect on the network formation, although the detected gelation was not related to conversion, and shrinkage was not investigated.

Curing reactions of cross-linked polymers are usually accompanied by cure shrinkage leading to internal stresses especially in multi-material assemblies, that is, if the material is not allowed to shrink freely, but is constrained, for example by a rigid substrate. In photocuring systems, shrinkage is crucial as, for example, in the case of acrylates, which are used as adhesives, coatings, and for printing applications (Davidson 1999). It was found that during network formation, the material shrinks freely up to the point where gelation sets in (Lange et al. 1995). After gelation, internal stresses start to build up, whereas the largest proportion is formed after vitrification (Wen et al. 2002). The internal stress level for coatings was generally approximated as the product of modulus of cured coating times shrinkage after solidification (Croll 1979) or gelation until the end of cure (Lange et al. 1997). This approximation was confirmed for cross-linked epoxies and moderately cross-linked acrylates; for very densely cross-linked acrylates, the obtained values were far too high (Lange et al. 1997).

This study concentrated on highly functional, hyperbranched acrylates and their reactive blends. This class of dendritic molecules offers an interesting perspective to reduce shrinkage (Wan et al. 2000; Klee et al. 2001; Kou et al. 2003). The aim was to identify the effect of gelation and vitrification on the internal stress level, with attention paid to the influence of intensity. To this end, photorheology data were combined with chemical conversion analysis, in the form of time-intensity transformation diagrams.

\section{Materials and methods}

Materials

Figure 1 depicts the structures of the different acrylate monomers studied, and Table 1 gives an overview of their physical and chemical properties. For the hyperbranched a) Di-Pentaerythritol Hexaacrylate (DPHA)

b) Segment of Acrylated Boltorn $\mathrm{H} 2 \mathrm{O}$
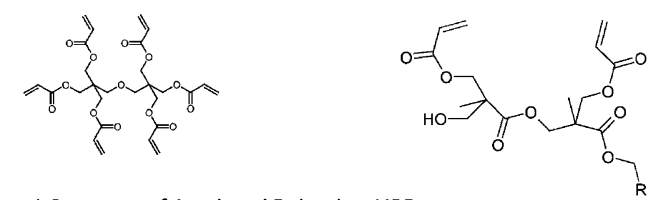

c) Segment of Acrylated Polyether HBP

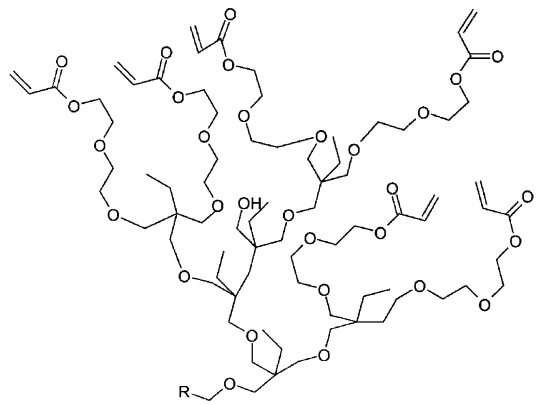

Fig. 1 Structures of the acrylate monomers studied. For the hyperbranched polymers, only one sample branch is shown. $R$ denotes the core molecule, from out of which grow four branches. Reprinted from (Schmidt et al. 2005a,b) with permission from Wiley-VCH

polymers, only one sample branch is shown because every single hyperbranched polymer (HBP) molecule has a different structure. Di-pentaerythritol hexaacrylate (DPHA, UCB Chemicals) is an acrylate monomer with, theoretically, six functional groups, but on average, only five functional groups. Two HBPs were also examined. The first one was based on a 16-hydroxyl functional secondgeneration hyperbranched polyester (Boltorn ${ }^{\circledR}$ H20, Perstorp $\mathrm{AB}$, Sweden) giving a 13-functional polyester acrylate (called acrylated Boltorn H20). The second one was based on a third-generation hyperbranched polyether

Table 1 Physical properties of the examined monomers

\begin{tabular}{lllll}
\hline Property & Unit & DPHA & $\begin{array}{l}\text { Acr. } \\
\text { Boltorn } \\
\text { H20 }\end{array}$ & $\begin{array}{l}\text { Acr. } \\
\text { polyether } \\
\text { HBP }\end{array}$ \\
\hline Core & & Aliphatic & $\begin{array}{l}\text { Polyester } \\
\text { HBP }\end{array}$ & $\begin{array}{l}\text { Polyether } \\
\text { HBP }\end{array}$ \\
Theor. & & & 16 & 32 \\
$\quad$ functionality & & & & \\
Actual & & 5 & 13 & 29 \\
functionality & & & & \\
$M_{\mathrm{n}}$ & $\mathrm{g} / \mathrm{mol}$ & $<520$ & 1,434 & 3,577 \\
$M_{\mathrm{w}}$ & $\mathrm{g} / \mathrm{mol}$ & 520 & 4,110 & 8,521 \\
Newtonian & $\mathrm{Pa} \cdot \mathrm{s}$ & 26 & 365 & 6 \\
$\quad$ viscosity & & & & \\
AEW & $\mathrm{g} / \mathrm{mol}$ & 104 & 316 & 294 \\
$\begin{array}{l}\text { DB (Fréchet) } \\
T_{\mathrm{g}} \text { monomer }\end{array}$ & & - & 0.43 & 0.4 \\
$T_{\mathrm{g}}$ polymer/at & ${ }^{\circ} \mathrm{C}$ & -36 & -26 & -55 \\
conversion & & $68 / 73 \%$ & $126 / 73 \%$ & $28 / 83 \%$ \\
\hline
\end{tabular}

$M_{n}$ Number molecular weight, $M_{w}$ mass molecular weight, $A E W$ acrylated equivalent weight, $D B$ degree of branching 
polyol (synthesized by Perstorp AB, Sweden) giving a 29functional polyether acrylate (called acrylated polyether HBP).

The polyester HBP was derived from the condensation of 2,2 bis-hydroxymethyl proprionic acid (bis-MPA; Malmström et al. 1995). The polyether HBP was synthesized by ringopening polymerization of alkoxylated TMPO derivatives (3-ethyl-3-[hydroxymethyl]oxetane, Perstorp AB, Sweden; Magnusson et al. 1999). Acrylation was carried out according to the conventional preparation of acrylic esters by condensation of the polyol with acrylic acid.

Although both syntheses lead to imperfect branching and significant polydispersity, HBPs conserve the essential features of dendrimers, i.e., high end group functionality and a globular architecture. The number of acrylate functions per monomer, and the molecular weight, were according to the specifications of the suppliers. The degree of branching was taken respectively from the work of Rodlert et al. (2004) on hyperbranched aliphatic polyesters and from that of Magnusson et al. (1999) on hyperbranched aliphatic polyether.

The photoinitiator was 1-hydroxy-cyclohexyl-phenylketone (Irgacure ${ }^{\circledR} 184$, Ciba Specialty Chemicals), at a concentration equal to $1 \mathrm{wt} \%$. It showed good solubility in the acrylate monomers.

The glass transition temperature of the monomers was measured by means of DSC (TA Instruments Q100) at a heating rate of $10 \mathrm{~K} / \mathrm{min}$ at the middle point of the transition. The glass transition temperature of the UV-cured polymers was determined by means of dynamic mechanical analysis (Rheometric Scientific RSA) in a three-point bending geometry on rectangular samples. Tests were performed at an excitation frequency of $1 \mathrm{~Hz}$ and a heating rate of $10 \mathrm{~K} / \mathrm{min}$, and the glass transition was defined as the maximum in the tangent of the phase angle between the loss and the storage moduli. The conversion state of the cured polymers was determined using Fourier transform infrared spectroscopy.

\section{Photorheometry}

Refined photorheology for fast-curing systems has been described elsewhere (Schmidt et al. 2005a,b), and a short summary is given here. The experiments were carried out on a strain-controlled dynamic rotational rheometer (ARES, Rheometrics Scientific, 2kFRT transducer), combined with a precision UV-light generator (Novacure N2000 spotcure, Hg UV lamp with $78 \%$ UV-A), with a special UV-coupling fixture. A novel acquisition and data treatment algorithm was developed in which the strain and the torque signal were acquired at a sampling rate of 10,000 times the excitation frequency (limited to $16 \mathrm{~Hz}$ by the rheometer) and treated independently.
The data treatment algorithm included the following steps: oversampling, to increase the signal to noise ratio (Wilhelm 2002) followed by an adaptive notch-filtering algorithm (Widrow and Stearns 1985) for efficiently filtering out noise at discrete frequencies leading to a narrowband signal. Figure 2 shows a segment of the torque signal after oversampling and the improvement of the signal quality due to adaptive denoising. Subsequently, the so-called analytical signal was formed, as the sum of the filtered signal and its Hilbert transform as imaginary part. The magnitude of the analytical signal corresponds to its envelope. From the envelopes of torque and strain signal, the absolute value of the complex shear modulus was calculated using the rheological function of the plate-plate tool. Gelation, corresponding to the transition from a viscous liquid to an elastic solid, was determined from the crossover of storage and loss moduli, that is, the tangent of the phase angle between strain and torque signals being equal to one. The Winter-Chambon criterion for determination of gelation (Winter and Chambon 1986; Winter and Mours 1997) could not be applied, as discussed in Schmidt et al. $(2005 \mathrm{a}, \mathrm{b})$, due to the limited frequency range of the rheometer. Steeman et al. (2004) came to the same conclusion when discussing whether a superposition of sine waves of different frequencies, as proposed by Chiou et al. (1996), would be applicable for fast UV-curing acrylates (a so-called multi-wave test). Vitrification was detected from a maximum of the phase angle plotted vs curing time (Lange et al. 2000). The present technique has a time resolution of $1 \mathrm{~ms}$, a stress resolution of $100 \mathrm{~Pa}$, and is limited to moduli smaller than about $70 \mathrm{MPa}$ for the chosen tool geometry $(0.1-\mathrm{mm}$ sample thickness, 8 -mm diameter parallel-plate tool, $10 \%$ strain) due to the compliance of the

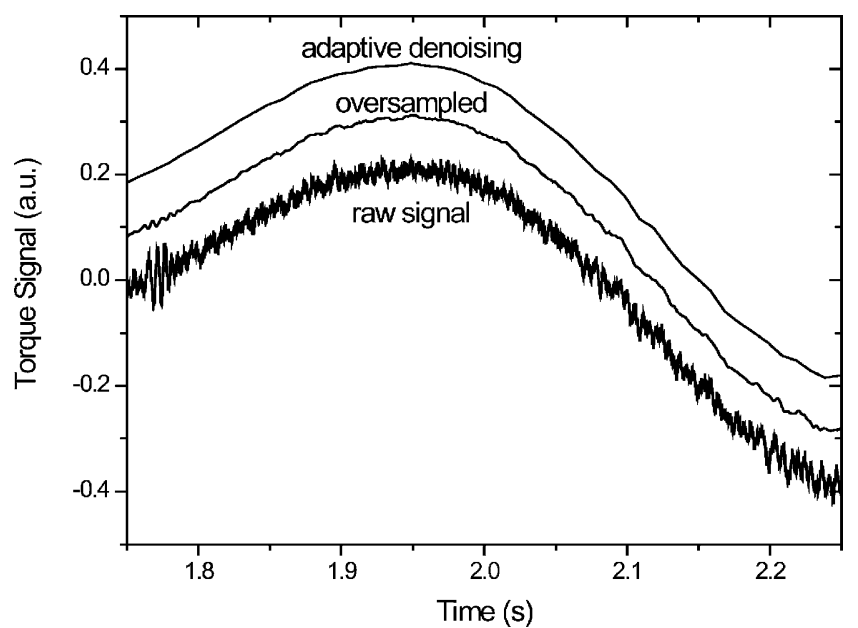

Fig. 2 Segment of the torque signal showing the improvement in signal quality of the measured signal (lower curve) due to oversampling (middle curve) and subsequent adaptive de-noising (upper curve). The curves were shifted upwards for improved legibility. Reprinted from (Schmidt et al. 2005a,b) with permission from Vincentz 
transducer. As discussed in Schmidt et al. (2005a,b), for a sample thickness of $0.1 \mathrm{~mm}$, and the given photoinitiator, the intensity loss in the sample was calculated to be equal to $9 \%$. The conversion rate and maximum conversion were found to scale with the intensity to the power 0.4 and 0.08 , respectively (Schmidt et al. 2007), so that the relative conversion gradient through the sample thickness was lower than $5 \%$.

\section{Photo DSC}

The heat of the photo-polymerization reaction was measured by means of photo DSC (Perkin Elmer DSC7, equipped with a UV-coupling cell). The cell comprised a lens that focused the UV light onto the open aluminum sample pans. The sample holders were sealed with windows that let the UV light pass through to the sample and the reference. An IR filter was used to cut out the IR part of the lamp spectrum. The sample space was flushed with nitrogen. The UV intensity was measured with the Solatell Sola-Check ${ }^{\mathrm{TM}}$. The photo DSC measurements led to curves showing acrylated double-bond conversion as a function of time.

The measurements were carried out at intensities ranging from 2 to $20 \mathrm{~mW} / \mathrm{cm}^{2}$, and the results were analyzed using an autocatalytic model (Chandra and Soni 1993; Chandra et al. 1993; Andrzejewska et al. 2001), including power-law dependence of conversion on intensity (Andrzejewska et al. 2001; Schmidt et al. 2007) To assure measurement conditions comparable to photorheometry, a sample weight of about $7 \mathrm{mg}$ was chosen, leading to a $250-\mu \mathrm{m}$-thick sample. The mean UV intensity of the sample was calculated as $89 \%$ of the incident intensity, which is similar to the $91 \%$ of the incident intensity, determined for photorheometry (Schmidt et al. 2005a,b).

Internal stress and Young's modulus measurements

The in-plane internal stress of acrylate coatings was determined from the curvature of coated aluminum beams. Because the elastic modulus of the coating during cure under the available UV intensity was unknown, the stress was calculated according to Stoney's model (Stoney 1909). The substrate was a 0.3 -mm-thick aluminum strip, $180 \mathrm{~mm}$ long and $8 \mathrm{~mm}$ wide, which was degreased and treated with a silane compound (2-propenoic acid, 2-methyl-,3-(trimethoxysilyl)propyl, Silquest A-174, GE Silicones) to promote adhesion of the acrylate coating. The acrylate was diluted in tetrahydrofurane, applied onto the aluminum strip, and the solvent was evaporated for $2 \mathrm{~h}$ at $80{ }^{\circ} \mathrm{C}$. The experiments were conducted under nitrogen atmosphere at a UV intensity of $40 \mathrm{~mW} / \mathrm{cm}^{2}$. The coating thickness was typically between 200-300 $\mu \mathrm{m}$, and therefore, direct comparison of conversion measured in DSC and internal stress measured from beam bending was possible.

The Young's modulus was measured on rectangular specimens $\left(20 \times 4 \times 0.15 \mathrm{~mm}^{3}\right)$ using a miniature tensile tester (Minimat, Rheometric Scientific), equipped with video extensometry, with strain resolution better than 0.001. The samples were cured under UV light at an intensity of $40 \mathrm{~mW} / \mathrm{cm}^{2}$. Their thickness, hence their conversion state, were comparable to the DSC and beam bending samples.

\section{Results and discussion}

Photorheology analysis of acrylated HBP reactive blends

Figure 3 compares the phase angle between stress and strain for DPHA, acrylated Boltorn H20, and two reactive blends, cured at $20 \mathrm{~mW} / \mathrm{cm}^{2}$. As already found for a lower UV intensity (Schmidt et al. 2005a,b), the gelation of acrylated Boltorn H20 was delayed compared to that of DPHA. For both reactive blends containing 20 and $50 \mathrm{wt} \%$ acrylated Boltorn H20, this was not the case. However, a significant difference was observed for the further course of the phase angle $\delta$. For DPHA, a peak of $\tan \delta$ was found, which was attributed to vitrification (Lange et al. 2000). Adding acrylated Boltorn $\mathrm{H} 20$ erased the vitrification peak, presumably because of the increase in the glass transition temperature of HBP blends (Schmidt et al. 2007). Acrylated Boltorn H20 and the two reactive blends kept their viscoelastic characteristics up to a higher reaction level, which should help relaxing the stress, hence reducing the final internal stress level. As shown in Fig. 4, the modulus build-up of acrylated Boltorn $\mathrm{H} 20$ and its reactive blends with DPHA was retarded compared to the

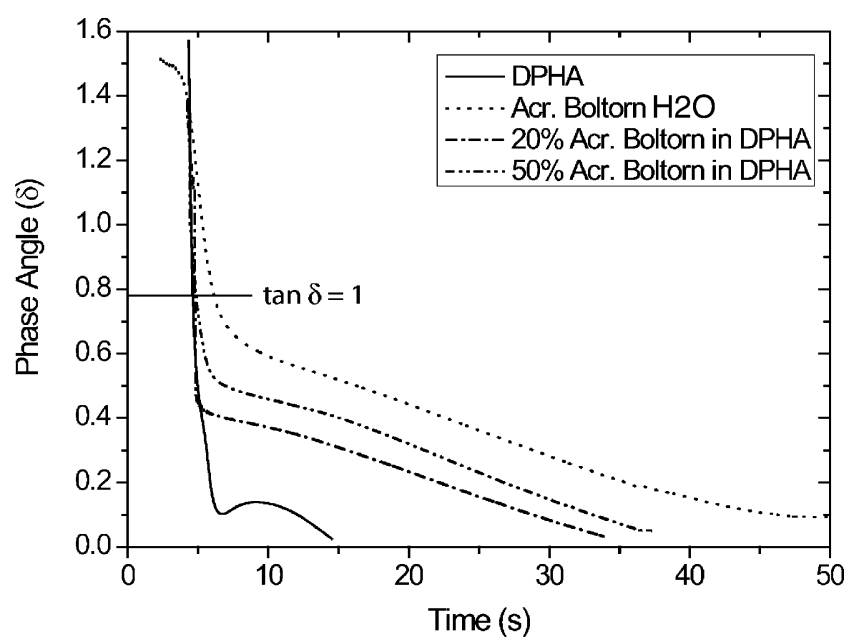

Fig. 3 Phase angle as a function of time for pure DPHA, acrylated Boltorn H20, and their blends, cured at $20 \mathrm{~mW} / \mathrm{cm}^{2}$ 


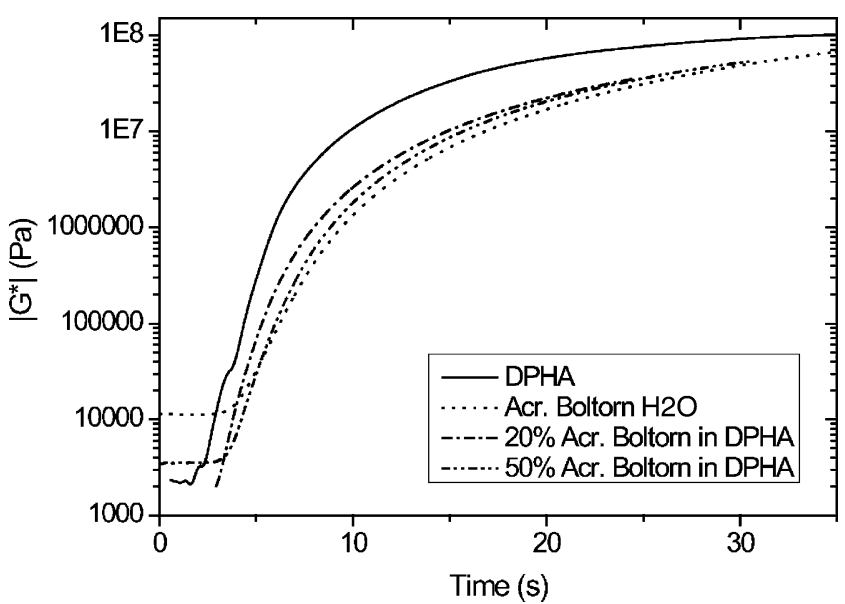

Fig. 4 Absolute value of the complex shear modulus as a function of time for pure DPHA, acrylated Boltorn $\mathrm{H} 20$, and their blends, cured at $20 \mathrm{~mW} / \mathrm{cm}^{2}$

case of pure DPHA, which should also contribute to a further reduction in internal stresses.

Equivalent information for reactive blends of DPHA and Polyether HBP were plotted in Figs. 5 and 6. Unlike acrylated Boltorn $\mathrm{H} 20$ blends, the introduction of Polyether HBP reduced the time to gel and to vitrify, with resulting earlier modulus build-up compared to pure DPHA. The differences in the final level of Young's modulus result from changes in ultimate conversion and glass transition temperature of the cured materials, as discussed in the final section.

Influence of HBPs on gelation, vitrification, and internal stress in acrylates

In Fig. 7, conversion at the onset of gelation, determined from the $\tan \delta=1$ data in Figs. 3 and 5, conversion at

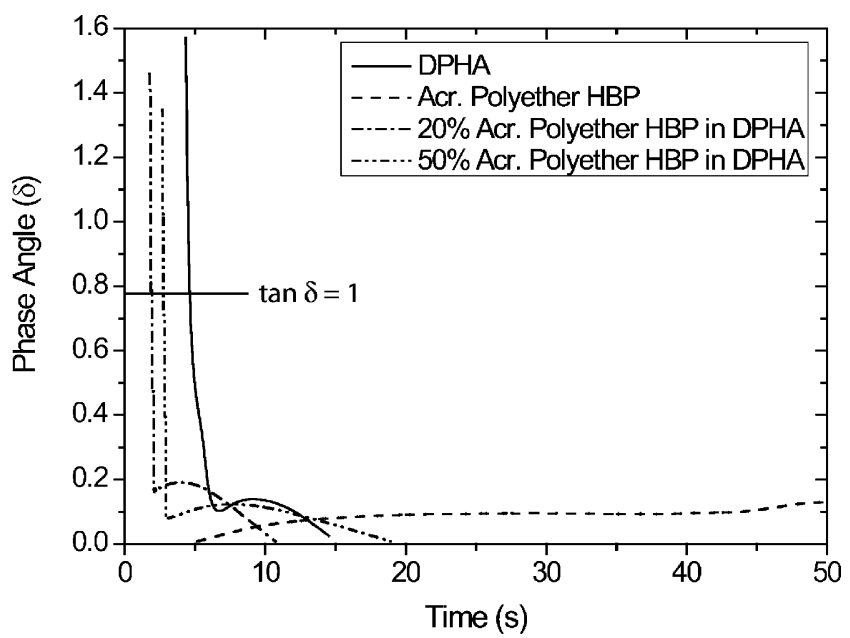

Fig. 5 Phase angle as a function of time for pure DPHA, acrylated polyether HBP, and their blends, cured at $20 \mathrm{~mW} / \mathrm{cm}^{2}$

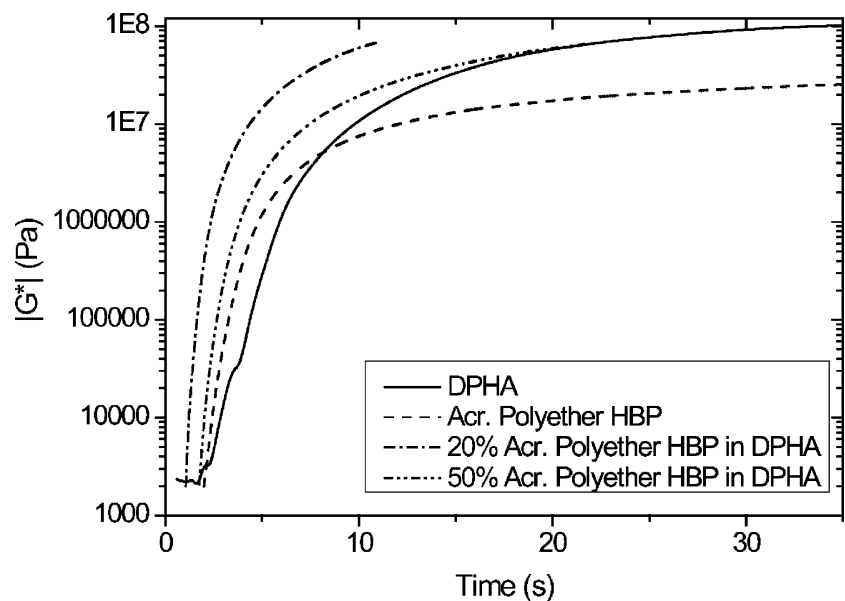

Fig. 6 Absolute value of the complex shear modulus as a function of time for pure DPHA, acrylated polyether HBP, and their blends, cured at $20 \mathrm{~mW} / \mathrm{cm}^{2}$

vitrification, and maximum conversion, determined from photo DSC (Schmidt et al. 2007), are plotted as a function of HBP concentration in DPHA. Gelation was not delayed to higher conversions by introducing HBPs. Instead, a slight shift of conversion at vitrification was detected: from $32 \%$ for DPHA to $36 \%$ for a $50: 50$ DPHA/acrylated Boltorn $\mathrm{H} 20$ blend and to $43 \%$ for a 50:50 DPHA/acrylated Polyether HBP blend. Delayed vitrification in HBP reactive blends should, in principle, reduce the internal stress, although the dependence of the ultimate glass transition temperature $T_{\mathrm{g}}^{\infty}$ of the blends on their composition may counteract this reduction because higher conversion may be reached when curing at a temperature close to $T_{\mathrm{g}}^{\infty}$, which is indeed the case for the acrylated Polyether blends.

Figures 8 and 9 compare the internal stress and Young's modulus of pure DPHA and HBPs and their blends cured at $40 \mathrm{~mW} / \mathrm{cm}^{2}$. Of the three pure acrylates, DPHA showed the

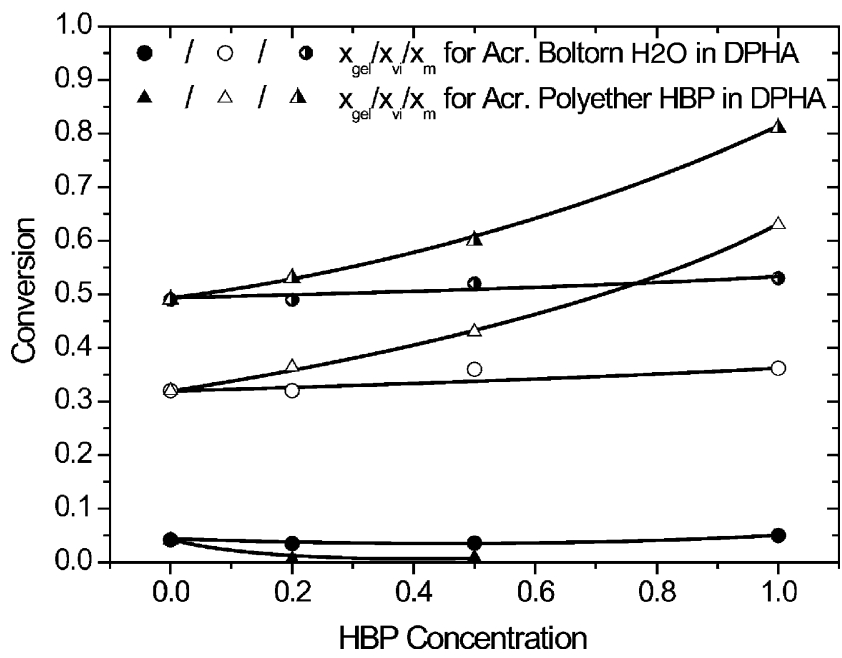

Fig. 7 Dependence of the conversion at gelation $x_{\text {gel }}$ and at vitrification $x_{\mathrm{vi}}$ on composition determined from photo DSC and photorheology, respectively. Lines are guides for the eye 


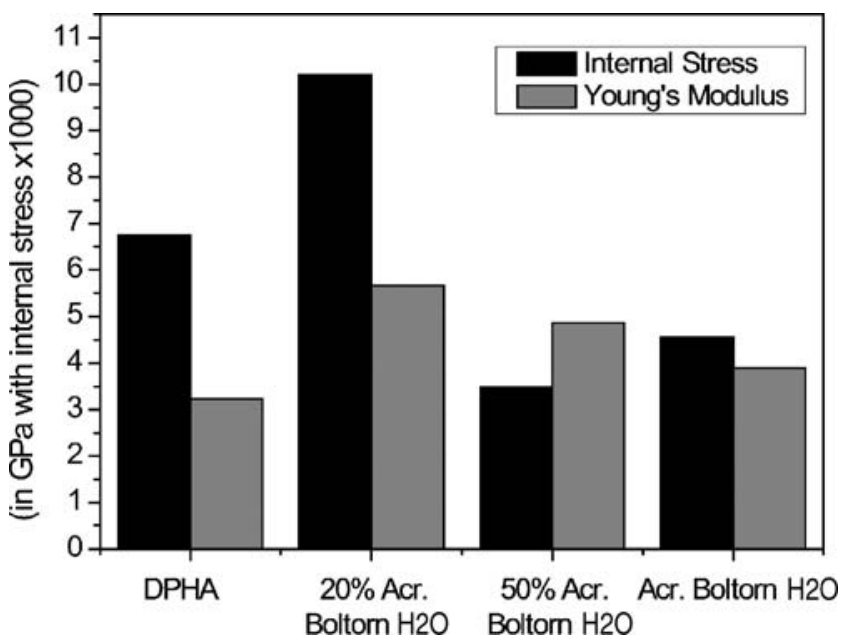

Fig. 8 Internal stress level and Young's modulus of cured films of DPHA, acrylated Boltorn $\mathrm{H} 20$, and their reactive blends, cured at $40 \mathrm{~mW} / \mathrm{cm}^{2}$

highest internal stress $(6.7 \mathrm{MPa})$ and a Young's modulus equal to $3.2 \mathrm{GPa}$. In contrast, the internal stress in the cured acrylated Boltorn $\mathrm{H} 20$ was reduced by $30 \%$, compared to that in DPHA, while at the same time having the highest Young's modulus of all three materials (3.9 GPa).

Adding $20 \mathrm{wt} \%$ of acrylated Boltorn H20 to DPHA led to a drastic increase in internal stresses to $10.2 \mathrm{MPa}$, presumably due to the high modulus of $5.7 \mathrm{GPa}$. An outstanding result was reported in the case of a blend of $50 \mathrm{wt} \%$ acrylated Boltorn H20 in DPHA. This material combined a low internal stress, approximately half of that of DPHA, and a Young's modulus as high as $5 \mathrm{GPa}$, i.e., more than $50 \%$ higher than that of DPHA. The contrasted values of Young's modulus and internal stress of the different blends reflect the dependence of the conversion at vitrification $x_{\mathrm{vi}}$ and the maximum conversion $x_{\mathrm{m}}$ on

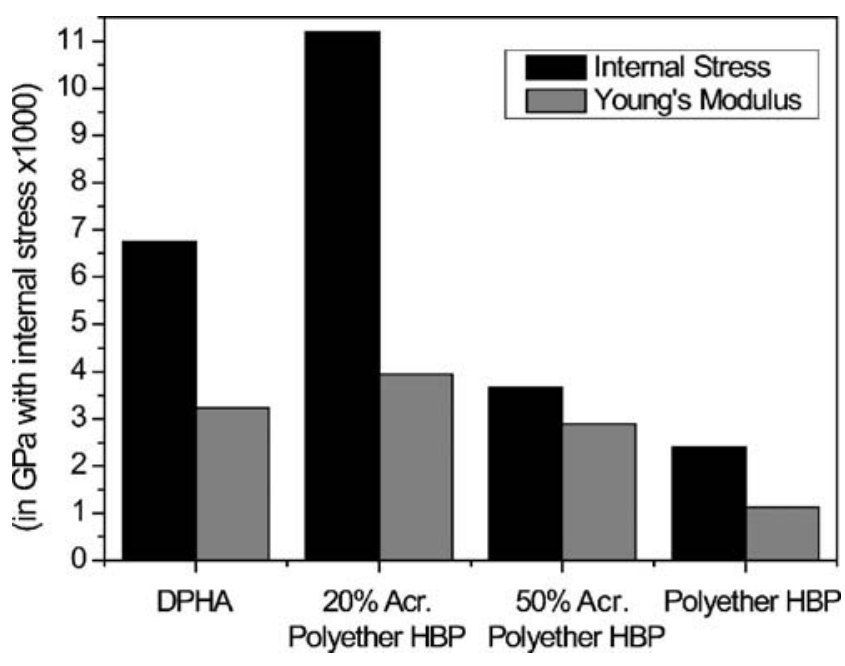

Fig. 9 Internal stress level and Young's modulus of cured films of DPHA, acrylated polyether HBP, and their reactive blends, cured at $40 \mathrm{~mW} / \mathrm{cm}^{2}$

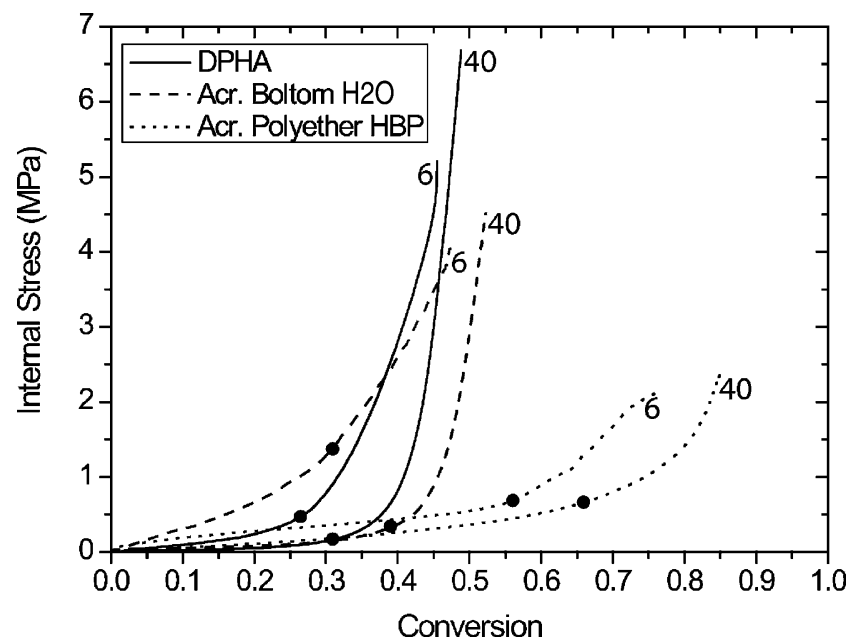

Fig. 10 Internal stress vs conversion. For each, the intensity is indicated in $\mathrm{mW} / \mathrm{cm}^{2}$. The bold point marks the onset of vitrification

composition, as was investigated in a recent work (Schmidt et al. 2007) and is discussed in the final section.

For a blend of $20 \mathrm{wt} \%$ of acrylated polyether HBP in DPHA (Fig. 9), an internal stress of $11.2 \mathrm{MPa}$ was measured, compared to 6.7 MPa for DPHA and 2.4 MPa for acrylated polyether HBP. The blend of $50 \mathrm{wt} \%$ acrylated polyether HBP in DPHA was more beneficial, with a $46 \%$ reduction in internal stress and only a $10 \%$ reduction in stiffness compared to pure DPHA. Again, the composition dependence of Young's modulus on internal stress is discussed in the final section.

Influence of UV intensity on the dynamics of internal stress

Figure 10 compares the development of internal stress under two different light intensities, plotted vs conversion

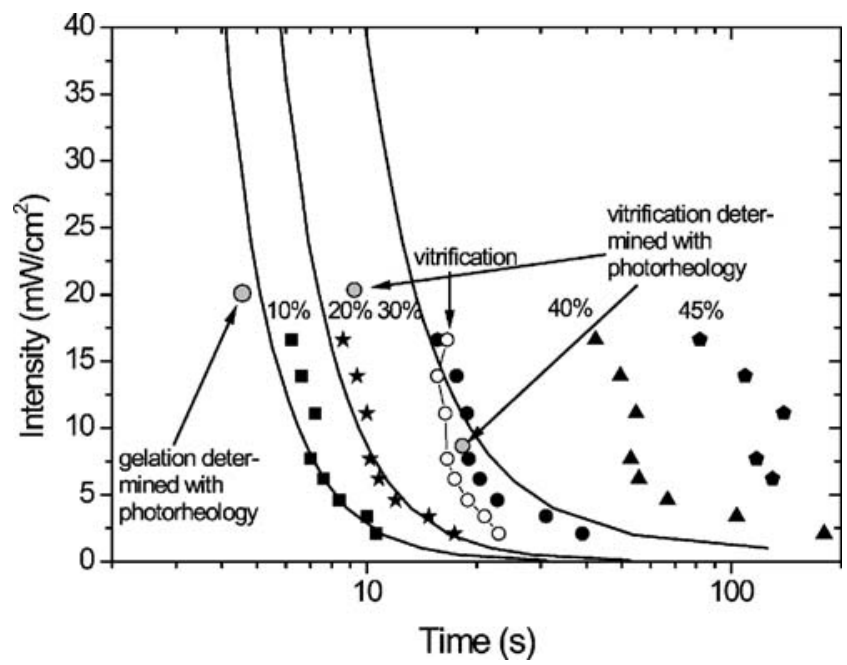

Fig. 11 Time-intensity transformation diagram of DPHA. See text for details 


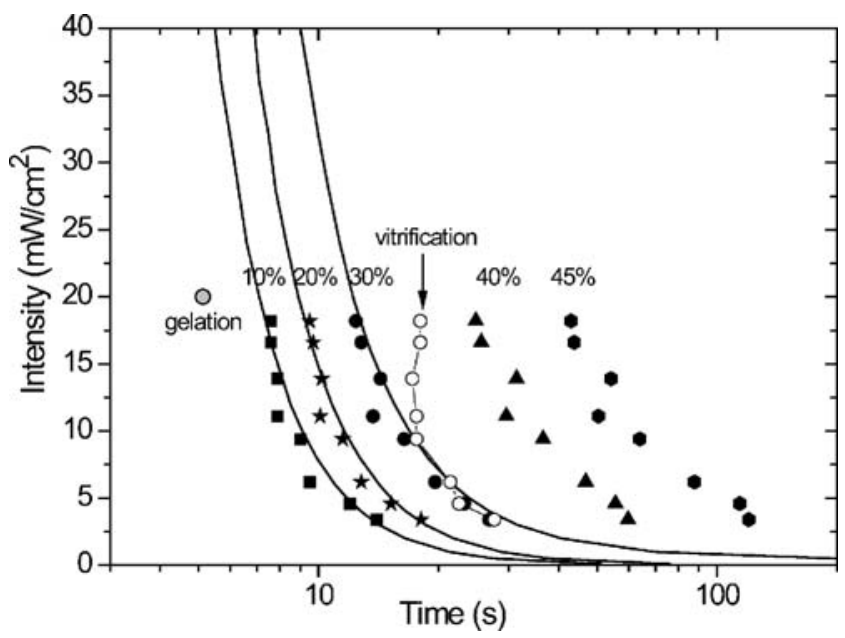

Fig. 12 Time-intensity transformation diagram of acrylated Boltorn H20. See text for details

with attention paid to vitrification (Schmidt et al. 2007). At a low intensity $\left(6 \mathrm{~mW} / \mathrm{cm}^{2}\right)$, significant stresses already built up before vitrification. Similar behavior was observed by Lange et al. in the case of acrylate and epoxy thermosets (Lange et al. 1995, 1997): In acrylates, about half of the stress already developed above $T_{\mathrm{g}}$, whereas in epoxies, this was not the case. In the case of acrylates, this result was attributed to the occurrence of micro-vitrification, in other words, the presence of small highly cross-linked domains in the rubbery matrix (Lange et al. 1999).

In contrast, at a high intensity $\left(40 \mathrm{~mW} / \mathrm{cm}^{2}\right)$, significantly less internal stress developed before the material started vitrifying. This is a consequence of volume relaxation processes lagging behind network formation, the more, the higher the intensity is (Kloosterboer 1988). Again, the higher final internal stress level obtained for films cured at higher intensities is caused by their higher ultimate conversion. The above findings indicate that stress

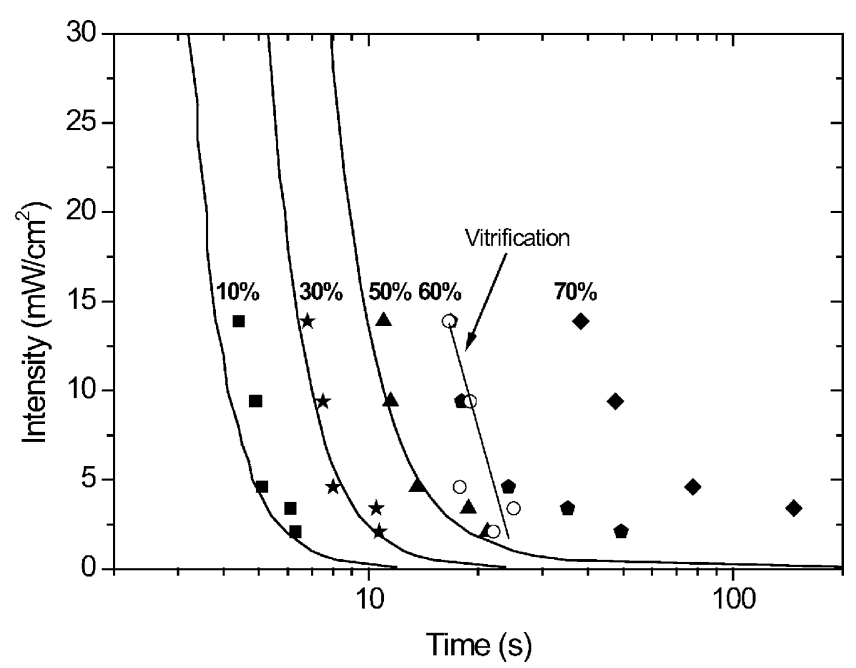

Fig. 13 Time-intensity transformation diagram of acrylated polyether HBP. See text for details

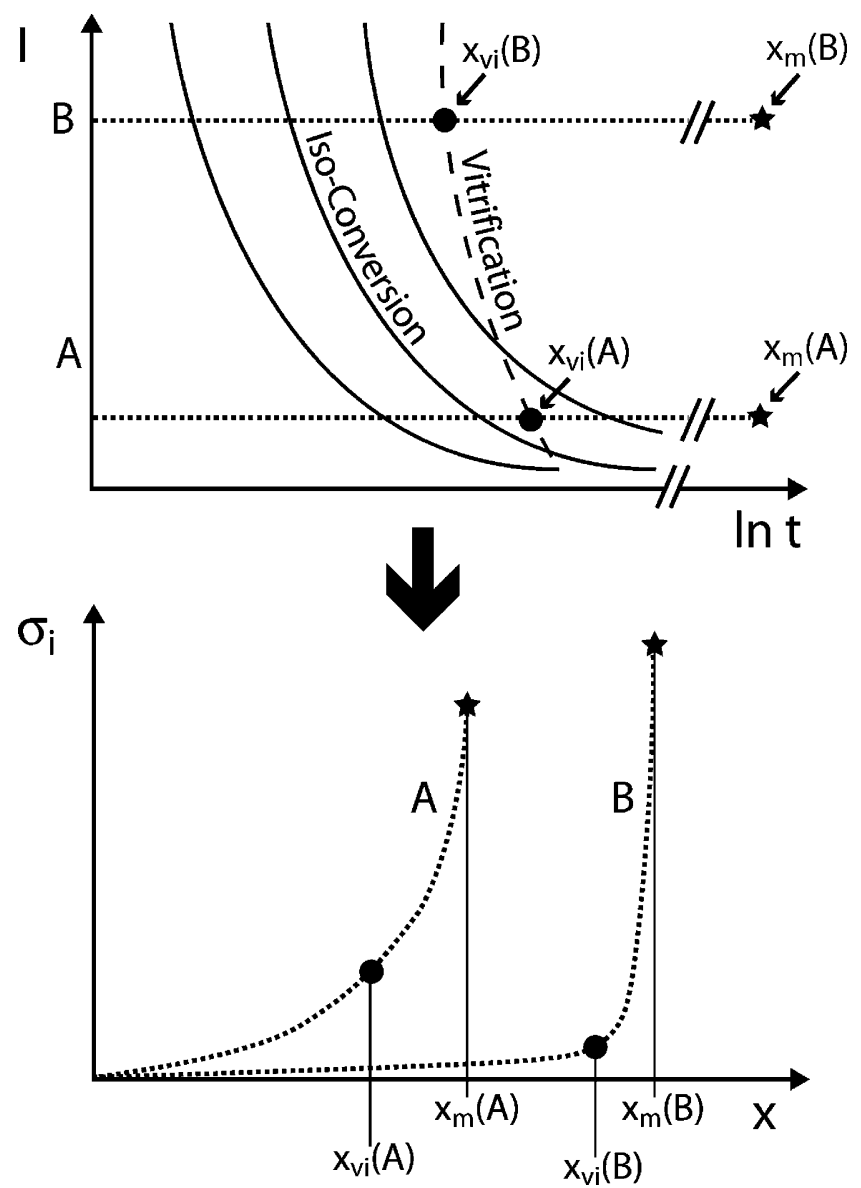

Fig. 14 Illustration of the dynamics of internal stress: Curing at a lower intensity (A) leads both to vitrification at lower conversion $x_{\mathrm{vi}}$, which results in earlier internal stress build-up, and also to limited maximum conversion $x_{\mathrm{u}}$, and thus, limited final stress, whereas curing at a higher intensity (B) leads to later stress build-up but higher final stress

dynamics result from competing processes: firstly, enhanced viscoelastic behavior (hence stress relaxation) in the case of high acrylate equivalent weight and high intensity, the rate of which depends on $T_{\mathrm{g}}^{\infty}-T_{\text {cure }}$, and secondly, modulus build-up (hence stress increase) upon vitrification up to final conversion (Croll 1979), which also depends on $T_{\mathrm{g}}^{\infty}-T_{\text {cure, }}$ and moreover increases with increasing intensity.

\section{Time-intensity transformation diagrams}

The conversion data and modeled iso-conversion curves up to vitrification are combined with gelation and vitrification in form of time-intensity transformation diagrams depicted in Figs. 11, 12, and 13, for DPHA, acrylated Boltorn H20, and acrylated polyether HBP, respectively. It is evident that the intensity has a considerable influence on conversion (Decker et al. 1996), and that the intensity dependence of conversion and vitrification is different (Schmidt et al. 2007), represented by the different slopes of iso-conversion 
and vitrification lines. For all three materials, it is also evident that vitrification was shifted to higher conversions for higher intensities. This explains the shape of the stress vs conversion curves measured in Fig. 10, as illustrated in Fig. 14. Curing at a low intensity (a) leads to both earlier vitrification, hence earlier internal-stress build-up, and also to limited maximum conversion and, therefore, limited final stress. Curing at a higher intensity (b) leads to later stress build-up but higher final stress.

The reduced stress for the acrylated Boltorn $\mathrm{H} 20$ results from the delayed vitrification and is also a direct consequence of its higher acrylate equivalent weight compared to that of DPHA. The major part of the internal stress build-up happens in the vitreous state: Adding $20 \mathrm{wt} \%$ of acrylated Boltorn H20 to DPHA already increases the maximum conversion $x_{\mathrm{m}}$ by 0.03 , which is in agreement with a study by Payne et al. (1997), suggesting that a slight increase in conversion in the vitrified state has a considerable impact on the internal stress. The lower internal stress of a 50:50 DPHA/acrylated Boltorn $\mathrm{H} 20$ blend also results from delayed vitrification, shown in Fig. 7, allowing for more stress relaxation during isothermal photo-polymerization. The higher Young's modulus of the 50:50 DPHA/acrylated Boltorn $\mathrm{H} 20$ blend is related to its higher ultimate conversion (Fig. 7).

The high conversion levels of acrylated polyether HBP results from curing close to its $T_{\mathrm{g}}^{\infty}$, in other words, due to late vitrification. As seen from the vitrification data (Fig. 7), adding $50 \mathrm{wt} \%$ of acrylated polyether HBP to DPHA shifted vitrification to a 0.13 higher conversion, whereas for a blend of $20 \%$ of acrylated polyether HBP in DPHA, the conversion at vitrification was not affected. The resulting fast increase in Young's modulus in the vitrified state together with increased ultimate conversion explains the high level of stress of this blend.

This investigation enables low-stress UV-curable acrylate materials to be produced, based on careful control of process conditions and blend composition. This approach was successfully used for the development of high aspect ratio microstructures relevant for microfluidic devices (Jin et al. 2005).

\section{Conclusions}

The photocuring behavior of three different acrylates-Dipentaerythritol penta/hexaacrylate (DPHA) and two hyperbranched molecules (HBP) - was investigated with attention paid to the build-up of Young's modulus and internal stress. The analysis of experimental results leads to the following conclusions.

The internal stress of the acrylated HBPs was considerably reduced compared to that of the DPHA. Moreover, in the case of acrylated Boltorn $\mathrm{H} 20$, and of 50:50 reactive blends with DPHA, stress reduction was obtained combined with an increase in Young's modulus. The increased Young's modulus resulted from an increased conversion, whereas the reduced stress was a consequence of the later onset of macroscopic vitrification.

It was found, that for a higher intensity, higher final internal stresses develop, but that the stress build-up is shifted to higher conversions. This is firstly due to a shift of vitrification to higher conversions, and secondly, by the lag of volume relaxation behind network formation.

Acknowledgment Financial support from the Swiss National Science Foundation (SNF project \# 2100.063675.00) is gratefully acknowledged. Prof. Manfred Wilhelm from the Max Planck Institute for Polymer Research and Dr. Jean-Marc Vesin from the EPFL are thanked for their fruitful collaboration on photorheology. Furthermore, the authors would like to thank David James from Perstorp Specialty Chemicals, Dr. Aly Franck from TA Instruments, and Dr. André Fuchs from Ciba Specialty Chemicals for providing samples and useful advice.

\section{References}

Andrzejewska E, Bogacki MB, Andrzejewski M (2001) The autocatalytic model of photopolymerization of dimethacrylates. Polimery 46(7-8):549-551

Botella A, Dupuy J, Roche A-A, Sautereau H, Verney V (2004) Photo-rheometry/NIR spectrometry: an in situ technique for monitoring conversion and viscoelastic properties during photopolymerization. Macromol Rapid Commun 25:1155-1158

Chandra R, Soni RK (1993) Studies on kinetics of bulk polymerization of divinyl ester by radical-initiated thermal and photopolymerization. Polym Int 31:239-245

Chandra R, Soni RK, Murthy SS (1993) Studies on the kinetics of radical initiated photocopolymerisation of Di(vinyl 2-hydroxy propanoate)ether of bisphenol-A and monomers. Polym Int 31:305-314

Chiou B-S, English RJ, Khan SA (1996) Rheology and photo-crosslinking of thiol-ene polymers. Macromolecules 29:5368-5374

Chiou B-S, English RJ, Khan SA (1997) UV cross-linking of thiol-ene polymers: a rheological study. In: Scranton $\mathrm{AB}$, Bowman $\mathrm{CN}$, Pheiffer RW (eds) Photopolymerization: fundamentals and application. American Chemical Society, Washington, pp 150 166

Croll SG (1979) The origin of residual internal stress in solvent-cast thermoplastic coatings. J Appl Polym Sci 23:847-858

Davidson S (1999) Exploring the science, technology and applications of U.V. and E.B. curing. SITA Technology, London, UK

Decker C, Moussa K (1988) A new method for monitoring ultra-fast photopolymerizations by real-time infra-red (RTIR) spectroscopy. Makromolekul Chem 189:2381-2394

Decker C, Elzaouk B, Decker D (1996) Kinetic study of ultrafast photopolymerization reactions. J Macromol Sci Pure Appl Chem A33(2):173-190

Enns JB, Gillham JK (1983) Time-temperature-transformation (TTT) cure diagram: modeling the cure behaviour of thermosets. J Appl Polym Sci 28:2567-2591

Gillham JK (1983) The time-temperature-transformation (TTT) state diagram and cure. In: Seferis JL, Nicolais L (eds) The role of the polymeric matrix in the processing and structural properties of composite materials. Plenum Press, New York, pp 127-145 
Jakubiak J, Sionkowska A, Lindén L-Å, Rabek JF (2001) Isothermal photo differential scanning calorimetry-crosslinking polymerization of multifunctional monomers in presence of visible light photoinitiators. J Therm Anal Calorim 65:435-443

Jin Y-H, Schmidt LE, Leterrier Y, Cho Y-H, Månson J-AE (2005) Fabrication process of low-stress UV-curable hyperbranched polymers for microfluidic applications. NanoTech 2005, the 9th annual european conference on micro \& nanoscale technologies for the biosciences, Montreux, Switzerland, Nov. 15-17

Khan SA, Plitz IM, Frantz RA (1992) In situ technique for monitoring the gelation of UV curable polymers. Rheol Acta 31:151-160

Klee JE, Schneider C, Hölter D, Burgath A, Frey H, Mülhaupt R (2001) Hyperbranched polyesters and their application in dental composites: monomers for low shrinking composites. Polym Adv Technol 12(6):346-354

Kloosterboer JG (1988) Network formation by chain crosslinking photopolymerization and its applications in electronics. Adv Polym Sci 84:1-61

Kou H-G, Asif A, Shi W-F (2003) Hyperbranched acrylated aromatic polyester used as a modifier in UV-curable epoxy acrylate resins. Chin J Chem 21:91-95

Lange J, Toll S, Månson J-AE, Hult A (1995) Residual stress build-up in thermoset films cured above their ultimate glass transition temperature. Polymer 36(16):3135-3141

Lange J, Toll S, Månson J-AE, Hult A (1997) Residual stress build-up in thermoset films cured below their ultimate glass transition temperature. Polymer 38(4):809-815

Lange J, Ekelöf R, George GA (1999) Indications of micro-vitrification during chainwise cross-linking polymerisation. Polymer 40:35953598

Lange J, Altmann N, Kelly CT, Halley PJ (2000) Understanding vitrification during cure of epoxy resins using dynamic scanning calorimetry and rheological techniques. Polymer 41:5949-5955

Lee SS, Luciani A, Månson J-AE (2000) A rheological characterisation technique for fast UV-curable systems. Prog Org Coat 38:193-197

Lee KJ, Choi JY, Lim BS (2003) Time-temperature-intensitytransformation cure diagram for visible light curable dimethacrylate resins. Polym J 35(10):778-784

Magnusson H, Malmström E, Hult A (1999) Synthesis of hyperbranched aliphatic polyethers via cationic ring-opening polymerization of 3-ethyl-3-(hydroxymethyl)oxetane. Macromol Rapid Commun 20:453-457
Malmström E, Johansson M, Hult A (1995) Hyperbranched aliphatic polyesters. Macromolecules 28:1698-1703

Payne JA, Francis LF, McCormick AV (1997) The effects of processing variables on stress development in ultraviolet-cured coatings. J Appl Polym Sci 66:1267-1277

Rodlert M, Plummer CJG, Garamszegi L, Leterrier Y, Grünbauer HJM, Månson J-AE (2004) Hyperbranched polymer/montmorillonite clay nanocomposites. Polymer 45:949-960

Schmidt LE, Leterrier Y, Schmaeh D, Månson J-AE, James D (2005a) Structural and residual stress analysis of UV curable hyperbranched acrylates. RadTech Europe, Barcelona

Schmidt LE, Leterrier Y, Vesin J-M, Wilhelm M, Månson J-AE (2005b) Photorheology of fast UV curing multifunctional acrylates. Macromol Mater Eng 290:1115-1124

Schmidt LE, Leterrier Y, Schmäh $\mathrm{D}$, Månson J-AE, James D, Gustavsson E, Svensson LS (2007) Conversion analysis of acrylated hyperbranched polymers UV-cured below their ultimate glass transition temperature. J Appl Polym Sci (in press)

Steeman PAM, Dias AA, Wienke D, Zwartkruis T (2004) Polymerization and network formation of UV-curable systems monitored by hyphenated real-time dynamic mechanical analysis and near-infrared spectroscopy. Macromolecules 37:7001-7007

Stoney GG (1909) The tension of metallic films deposited by electrolysis. Proc R Soc Lond A Math Phys Sci 82:172-175

Wan Q, Schricker SR, Culbertson BM (2000) Methacryloyl derivitized hyperbranched polyester. 2. Photo-polymerization and properties for dental resin systems. J Macromol Sci Pure Appl Chem A37(11):1317-1331

Wen M, Scriven LE, McCormick AV (2002) Differential scanning calorimetry and cantilever deflection studies of polymerization kinetics and stress in ultraviolet curing of multifunctional (meth) acrylate coatings. Macromolecules 35:112-120

Widrow B, Stearns SD (1985) Adaptive signal processing. PrenticeHall, Englewood Cliffs, New Jersey

Wilhelm M (2002) Fourier-transform rheology. Macromol Mater Eng 287:83-105

Winter HH, Chambon F (1986) Analysis of linear viscoelasticity of a crosslinking polymer at the gel point. J Rheol 30(2):367382

Winter HH, Mours M (1997) Rheology of polymers near liquid-solid transitions. Adv Polym Sci 134:165-233 